\title{
TRAINING INTERVENTIONS APPLICABLE ACROSS SECTORS
}

\author{
Kavita Joshi \\ Professor, Research Scholar, Faculty of Management - MBA, \\ Navsahyadri Group of Institutes, Pune, India \\ Dr. K S Charak \\ Director, Faculty of Management - MBA, \\ Navsahyadri Group of Institutes, Pune, India
}

\begin{abstract}
One of the main differentiators for companies, particularly the manufacturing industries, is training and growth. The manufacturing industry training and development system in Pune needs a comprehensive overhaul. There is a lack of a systemic approach to the current training and development programmes, particularly with regard to the design and planning approach. For example, there was no fixed training and development schedule and, moreover, no such schedule was disseminated or displayed. The average number of training programs representing the organization's current training strategy is only 2, reflecting the institution's apathy for training and growth. If the employees' evidence is to be believed, then there is a lack of a consistent training and development program for manufacturing sectors and seldom are employees identified to external organizations. The training approach practiced is on job training and the resource person is most commonly internal resource individuals or company workers on most occasions. The recognition of training and development needs is one of the serious grievances put forward by workers and it has been ranked as one of the most significant factors affecting their decision to engage in training and development programs. With all of the above, a systematic and empirical approach to training and development must be developed by all organizations.
\end{abstract}

Key words: Training, training systems, review of training needs.

Cite this Article: Kavita Joshi and K S Charak, Training Interventions Applicable Across Sectors, International Journal of Management, 11(12), 2020, pp. 2699-2705. http://iaeme.com/Home/issue/IJM?Volume=11\&Issue=12

\section{INTRODUCTION}

By adopting and indeed promoting the process of globalization, liberalization and privatization, the Indian economy, which is the sixth largest economy in the world by GDP, has moved dramatically from protectionist and social democratic policies to market-based economies. In 
the Indian economy, manufacturing plays a significant role, accounting for nearly $16 \%$ of real GDP in FY12 and employing approximately $12.0 \%$ of India's labor force. The contribution made by the manufacturing sector to the real gross domestic product of India has increased over the years, but the rate of growth has been below expectations.

According to the 2017 Global Manufacturing Competitiveness Index (GMCI), prepared by the US Council on Competitiveness and Deloitte, India ranks 39th out of 138 countries in the world. Radical developments in all sectors except health and primary education have led to the substantial increase in India's position. Looking ahead, with its index score expected to increase, India's competitiveness will grow higher. In addition, India is expected to strengthen its present position and to make a major change by jumping 6 positions ahead of its current position.

In developing countries, including India, the effect of the post-crisis slowdown on industrial growth has been relatively mild, but the downward trend in MVA has been substantial (Kanda, 2013). Low-level technology, higher input costs and poor quality infrastructure can be attributed to the country's lower contribution to manufacturing value added. In reality, it has done better in labor-intensive sectors, such as textiles, wearing apparel and leather goods, from traces back to centuries. Leaders in the MVA contribution industry need to pay attention to 2 major enablers, namely technology adoption and developing a professional workforce, to achieve a substantial improvement in the MVA contribution market. Never before have leaders realized that strategically exploiting the implementation of technology would help them remain on par with their global counterparts and dramatically increase their ability to deliver on the global market. In order to alleviate the numerous challenges, companies need to invest more in R\&D and build a pool of skilled and trained employees. But having said that this resource is very scary at the hands of Micro, Small and Medium Business, and they will seldom have the luxury of employing them for untested waters. The manufacturing sector is therefore primed for unprecedented shifts in the global context, regardless of whether it is linked to technology or human capital. Industries that take into account the current socio-legal climate can rarely afford to neglect the most important resource, namely human capital, and therefore invest in the preparation and growth of their workers to prepare them for potential challenges.

The role of training and development has been undisputed in achieving these goals, and there is plenty of evidence and literature to support this viewpoint. In reality, apart from tangible and immediate benefits, including employee morale and retention, the company itself would be the greatest beneficiary of any training and development efforts where long-term competitive advantage, including organizational development, can be achieved.

\section{REVIEW OF LITERATURE}

Training is a comprehensive way for employee development of current workers, according to Goldstein \& Ford, and increases the quality of new and existing employees in particular and organizations in general (Goldstein \& Ford, 2002). As supported by (Noe, Hollenbeck, Gerhart, $\&$ Wright, 2006), organizations expend a tremendous amount of money and time on training to promote employee learning. The outcomes of training efforts must therefore be fully provided (Dowling \& Welch, 2005). Therefore, it is important for organizations to revisit their training efforts and their results at regular intervals.

A study by Yadapadithaya and Jim Stewart (2003) on corporate training and growth policies and practices in India and Britain shows that the responsibility for training functions lies with HR or training specialists in more than 71 percent of Indian organisations, 55 percent of workers undergo training and a sum of Rs. 253.3 was spent on an employee as investment in training. In addition, the author estimates that 78.6 percent of Indian companies provide training with the goal of improving employee efficiency, quality and innovation. In order to evaluate T\&D performance, 89.3 percent of organizations perform training evaluations. The proportion of 
workers undergoing training is also much lower relative to global expectations, as found by the authors' findings.

Kate Hutchings, Cherrie J. Zhu, Brian K. Cooper, Yiming Zhang and Sijun Shao (2009) conducted an interesting study to understand their perceptions of the organization's training and development programs among semi-skilled employees, especially technicians. The survey found that participants mostly equate their success with training intervention in an organization and try to quantify the importance in terms of post-training rewards in the form of increments and promotions. 52.3 percent of respondents indicated that, after undergoing training, the company had not provided them with a pay raise, according to the author. 36.2 percent of respondents indicated that they had not been given an opportunity for advancement through training. 25.2 percent of respondents indicated that only their initial organizational membership was restricted to training. However, respondents agreed that training and development activities had a positive effect on their readiness for jobs, professional skills, interpersonal skills, team work, trust in the job and motivation to work.

Schmidt Steven W., contrary to the results of Kate Hutchings, Cherrie J. Zhu, Brian K. Cooper, Yiming Zhang and Sijun Shao (2009), (2009) found that none of the sociodemographic variables including age, schooling, race, ethnicity or organizational position influenced work training satisfaction in his study of training satisfaction in American and Canadian organizations. (Schmidt, 2009) In fact, the author concluded that the tenure of the respondent in the organization was much more important in influencing the satisfaction of training. The author was further able to differentiate training satisfaction according to the section in which his services were provided by the respondent. In the case of a customer service agent, while the level of initial satisfaction is higher, it starts to decrease with employee tenure and sharply rises for workers with more than 12 years of service tenure.

(Santos \& Stuart, 2003), stated that it was found that the effective transition of training depended on the opportunities and resources available for the implementation of new knowledge. A major factor responsible for any behavioral improvement expected from training was the view of trainees regarding the learning environment. Trainees with a good outlook about the learning process were more likely during training to adhere to behavioral changes. (2007: LI Chun Yan)

(Heyes, 1994), stressed the importance of a reward system in training that eventually influences the attitude of the trainee towards training, which in turn determines the effectiveness of the training. (Noe, 1986)'s, through its training efficiency model, defined the attitudes of participants about their employment and professions and their discernment of the working atmosphere that could have an effect on the results of training.

\section{METHODOLOGICALS}

In the present analysis, the goals of the research are focused on the research issue and the research premise. The goals are reported as follows

- In Pune, to recognize the current state of training development programs across manufacturing industries.

- To describe employees' attitude and perception towards the existing training and development programs.

- To describe the level of modifications across individual and organizational attributes in the existing training and development programs. 


\section{DESIGN OF ANALYSIS}

According to Saunders, Lewis and Thornhill (2009), study design can be divided into methods that are exploratory, descriptive and explanatory. A descriptive analysis technique, such as quantitative research, is used to perform this research. This analysis used a deductive approach. The primary data was collected through questionnaires for this reason. Simple random sampling is the sampling process. The approach is used because we request information from different blocks of Pune MIDC. The "employees" were the prime sampling unit in the current analysis. A report on employers about their understanding has been understood in addition to workers. So "Top Management executives" is the second sampling unit. 450 employees; 30 were approached and chosen from each of Pune District's 15 manufacturing industries along with top executives. Secondary data was obtained from multiple sources. It includes reference books, study journals, websites, records of dealers, government reports, newspapers, and other subjectrelated sources. In view of the scope of the work, it is agreed to limit the current research to the strategies used by the companies located in Pune MIDC. In view of the location, the large number of companies and the number of workers involved in the study, the sampling will be carried out using stratified random sampling methods from ten companies. Data from 10 participating firms, consisting of small, medium and large industries, workers, their immediate supervisors, decision-makers and HR employees from each of the companies, will be collected. Large and medium sized industries would be the sample size.

\section{DISCUSSION}

The survey consists of $80 \%$ of male respondents, which is in line with the prevalent social scenario in which females are minimally active because of social stigmas. In the 21-30 age group, 27.7 percent of the population is made up of respondents.

The number of staff in the 41-50 age group is 25.6 percent of the overall workforce included in the current survey. The number of workers who have either completed higher education or vocational training is 31 percent. Someone in the third of the study is a diploma holder, preceded to their credit by employees who have industrial training. Most of the respondents with less than 5 years of experience with the present organization are in the given sample. Most notably, one out of every three respondents indicated that the institute does not have a set training program schedule.

\section{Modifications in T\&D program}

Table 1 Modification in T\&D

\begin{tabular}{|l|l|r|r|l|l|}
\hline & & & & Valid & \multicolumn{1}{l|}{ Cumulative } \\
\hline & & Frequency & Percent & Percent & Percent \\
\hline Valid & yes & 312 & 83.2 & 83.2 & 83.2 \\
\hline & no & 63 & 16.8 & 16.8 & 100 \\
\hline & Total & 375 & 100 & 100 & \\
\hline
\end{tabular}

From the above table it can be seen that $83 \%$ of the respondents report that modifications in present $T \& D$ programs is required which needs immediate and considerable attention from the organizers of the T\&D programs. 
Table 2 Degree of modifications in Training and Development

\begin{tabular}{|l|r|r|r|r|l|}
\hline & Highly \\
Modifications & desirable & Desirable & $\begin{array}{l}\text { Can’t } \\
\text { Say }\end{array}$ & $\begin{array}{l}\text { Less } \\
\text { desirable }\end{array}$ & $\begin{array}{l}\text { Not } \\
\text { desirable } \\
\text { at all }\end{array}$ \\
\hline $\begin{array}{l}\text { Identification of training } \\
\text { needs }\end{array}$ & 19.7 & 22.7 & 24 & 19.2 & 14.4 \\
\hline Curriculum (Topics covered) & 16 & 23.5 & 21.6 & 26.1 & 12.8 \\
\hline Training methodology & 19.7 & 25.3 & 25.9 & 19.7 & 9.3 \\
\hline Selection of Trainers & 12.3 & 24.5 & 24 & 26.9 & 12.3 \\
\hline Selection of participants & 16 & 24.3 & 28 & 21.6 & 10.1 \\
\hline Any other & 17.9 & 20.5 & 28.3 & 19.7 & 13.6 \\
\hline Enhanced training frequency & 9.1 & 9.9 & 65.1 & 5.9 & 10.1 \\
\hline Duration of training & 12.5 & 15.5 & 25.3 & 21.1 & 25.6 \\
\hline
\end{tabular}

The above table indicates that the highest proportion of unsatisfied workers is 19.7 percent in terms of training needs recognition and training methodology. 44 percent of staff have shared their disappointment with the methodology of preparation. Employees tend to be pleased with the duration of training, and the highest percentage of employees who do not perceive any improvement in the duration of training is expected. The highest proportion of workers who are not aware of changes in the training domain belongs to the frequency of training and 65 percent of those employees. The view on the new system of selection of trainers seems to be divided by

Table 3 Extent of use of various training methods used

\begin{tabular}{|c|c|c|c|c|c|c|}
\hline Statement & $\begin{array}{l}\text { No } \\
\text { response }\end{array}$ & SA & Agree & $\begin{array}{l}\text { Can't } \\
\text { say }\end{array}$ & Disagree & SD \\
\hline $\begin{array}{l}\text { Our organization has a stated } \\
\text { organization policy for training and } \\
\text { employees are aware of it. }\end{array}$ & 15.7 & 18.1 & 19.7 & 21.9 & 12.3 & 12.3 \\
\hline $\begin{array}{l}\text { Management recognizes the } \\
\text { importance of T\&D as a strategy }\end{array}$ & 23.7 & 19.7 & 14.4 & 18.9 & 10.4 & 12.8 \\
\hline $\begin{array}{l}\text { Our organization has adequate budget } \\
\text { for organizing training programs }\end{array}$ & 4.5 & 12 & 16.5 & 41.3 & 12.8 & 12.8 \\
\hline $\begin{array}{l}\text { Management make ample efforts to } \\
\text { sensitize employees regarding } \\
\text { importance of training }\end{array}$ & 0 & 12.8 & 12.8 & 21.1 & 27.7 & 25.6 \\
\hline $\begin{array}{l}\text { The frequency of T\&D in our } \\
\text { organization is satisfactory }\end{array}$ & 9.1 & 12.8 & 9.9 & 22.7 & 26.9 & 18.7 \\
\hline $\begin{array}{l}\text { The methodology of identifying } \\
\text { training requirement is satisfactory }\end{array}$ & 4 & 5.9 & 16.8 & 24.3 & 23.5 & 25.6 \\
\hline $\begin{array}{l}\text { The resource person for T\&D training } \\
\text { program are knowledgeable }\end{array}$ & 6.7 & 7.2 & 12.8 & 26.4 & 22.9 & 24 \\
\hline $\begin{array}{l}\text { The present system of training } \\
\text { impartment is satisfactory }\end{array}$ & 7.2 & 13.6 & 17.3 & 24.3 & 20.3 & 17.3 \\
\hline $\begin{array}{l}\text { Employee get an opportunity to discuss } \\
\text { about their training needs with their } \\
\text { superiors }\end{array}$ & 9.9 & 11.2 & 15.7 & 24.5 & 18.4 & 20.3 \\
\hline $\begin{array}{l}\text { Our organization has fixed training } \\
\text { calendar }\end{array}$ & 4.3 & 11.7 & 11.7 & 29.1 & 19.7 & 23.5 \\
\hline
\end{tabular}

It can be observed from the table that the region of the current training method where the maximum number of respondents Is strongly convinced Is the is recognized as one of the 
techniques that will give the company a competitive advantage. The field of discrepancy in the existing training program, namely the sensitization of workers to training and the identification of the need for training methods, seems to be of concern to the largest number of respondents. $41 \%$ of respondents are not sure of the budgetary provision of training that is highest for any training sector. $37 \%$ of respondents agree with the assertion that the company has a specified training organization policy and employees are aware of it as opposed to $24 \%$ of employees who are not convinced of it. $44 \%$ of employees either agree or strongly agree with it. As compared to $20 \%$ of respondents who either agree or strongly agree that the T\&D training program resource person is competent, $47 \%$ of employees disagree or strongly agree with the same. $13 \%$ and $17 \%$ of respondents strongly support and agree that, compared to $37 \%$ of respondents who either disagree or strongly disagree with the same, existing training programs are satisfactory.

\section{CONCLUSION}

The average values of 3 constructs derived from factor analysis are far below 3 and we can therefore confidently conclude that most participants have proposed improvements to the current training and development program and therefore reject the null hypothesis that current training and development practices in Pune are adequate across manufacturing industries. The participants proposed improvements to the training curriculum and further inquiries should be made into the specific modifications needed by them. As stated by respondents, the training and development framework in Pune's manufacturing industries needs a comprehensive overhaul. There is a lack of a systemic approach to the current training and development programmes, particularly with regard to the design and planning approach. For example, there was no fixed training and development schedule and, moreover, no such schedule was disseminated or displayed. The average number of training programs representing the organization's current training strategy is only 2, reflecting the institution's apathy for training and growth. If the employees' evidence is to be believed, then there is a lack of a consistent training and development program for manufacturing sectors and seldom are employees identified to external organizations. The training approach practiced is on job training and the resource person is most commonly internal resource individuals or company workers on most occasions.

The recognition of training and development needs is one of the serious grievances put forward by workers and it has been ranked as one of the most significant factors affecting their decision to engage in training and development programs. With all of the above, a systematic and empirical approach to training and development must be developed by all organizations. First and foremost, companies need to orient their workers towards the aim of training and growth, not work rotation as viewed by them, but an important strategic tool for organizational development, on the other hand. In the long run, the scientific approach to training requires research, complemented by the participation of staff in the creation of training designs, would ensure an enthusiastic and productive contribution by staff.

\section{REFERENCES}

[1] ABDULLAH, H. (2009). Major challenges to the effective management of human resource training and development activities. The Journal of International Social Research, 11-16.

[2] Baggaa, A. (2016, Feb 08). Unless Urgent Steps Are Taken, Make in India Will Remain a NonStarter. The Wire.

[3] Brown, G. K., \& Gerhardt, W. M. (2002). Formative evaluation: an integrative practice model and case study. Personnel Psychology, 951-983. 
[4] C a ff a r e 11 a, R. S. (1988) . "P ro g r a m Development and Evaluation Resource Book for Trainers. New York: John Wiley \& Sons.

[5] Casio, W. (2000). Costing Human Resources:The Financial Impact of Behavior in Organizations.Cincinnati : South-Western.

[6] Cuming, M. W. (1980). The theory and practice of personnel management. London: Butler and Taller Ltd.

[7] Darraugh, B. (1991). "It takes Six (Six-step Model for Need Assessment)". T raining \& Development Journa, 21-23.

[8] Dean, J. (2011). http://www.evancarmichael. com/library/janet-dean/Step-Up-to-Staff. Retrieved June 14, 2017, from www.evencarmichel.com.

[9] Dena, W. P. (2003). Effective training model.Journal of Extension .

[10] Devi, R. V., \& Shaik, N. (2012). Training \& Development - A Jump Starter For Employee Performance And Organizational Effectiveness. International Journal Of Social Science \& Interdisciplinary Research, 30-36.

[11] Dowling, P., \& Welch, D . (2005). International Human Resource Management: Managing People in a Multinational Context. Manson: Thomson South-Western.

[12] Ekaterini Galanou, C.-V. P. (2009). A model for evaluating the effectiveness of middle managers' training courses: evidence from a major banking organization in Greece. International Journal of Training and Development, 221-245.

[13] Garvey, A. (2011, August 5). Hold on to your Talent Staff. Straits Times. Goldstein, I., \& Ford, J. (2002). HRM. Belmont: Wadsworth.

[14] Gordon, S. (1994). Systematic Training Program Design \& Maximizing Effectiveness and Minimizing Liability. Englewood Cliffs, N J: Prentice Hall.

[15] Graham, K., \& Mihal, W. (1986). "Can Your Management Development Needs Surveys be Trusted? Training \& Development Journal, 38-42.

[16] Gupta, C. (2007). Human Resources Management. NewDelhi: Sultan Chand \&Sons. 